\title{
Management Of Aspergillus Leaf Spot Diseases on Terminalia Catappa In Sokoto, Nigeria
}

\author{
*Nasiru A. M ${ }^{1}$ Ken-nwankwo J. C ${ }^{2}$ \\ *1 Department of Forestry \& Environment, Usmanu Danfodiyo University, Sokoto Nigeria \\ *Corresponding author: Muhammad Nasiru Abubakar, Department of Forestry \& Environment, UDUS, Sokoto Nigeria. \\ Email amnafad597@gmail.com Phone: +2348034566086
}

\begin{abstract}
Research on the diseased leaves of Terminalia catappa (tropical almond) was conducted in Usmanu Danfodiyo University Permanent site, Wammako local government, Sokoto. The locations where the diseased leaves were collected, purposively selected because of the abundance of the tree species in those locations. The objective was to identify fungal foliar diseases associated with Terminalia catappa and then develop control measures of the pathogen. Diseased leaves were collected and taken to the department of biological sciences, Mycology laboratory, Botany unit, Usmanu Danfodiyo University for identification. Aspergillus niger, Aspergillus ustus and, Aspergillus flavus were the fungal pathogens identified and suspected to be the cause of the foliar diseases on the tree species. Suncozeb, a broad-spectrum fungicide was obtained for the management of these diseases. The chemical was applied at different concentration rates $(50 \%, 100 \%$ and, $150 \%)$ and the zones of inhibitions were observed and measured. It was observed that the higher the concentration the higher the zones of inhibition; this was the case for all the organisms identified. Past research showed that high temperature makes this species prone to soil-borne pathogens and this is the case with the study area of this research. As part of the recommendation, since it was observed that $150 \%$ of Suncozeb clearly inhibited the growth of the pathogen to a certain level, a higher concentration of this same chemical will increase the inhibition zone and possibly bring a complete stoppage of the pathogen spread.
\end{abstract}

Keywords: Terminalia catappa, Aspergillus specie, Suncozeb, Disease and Fungi

\section{Introduction}

Combretaceae is one of the largest families of flowering plants including trees, shrubs and, lianas comprising about 20 genera and 600 species. Terminalia is a genus of large trees belonging to the family Combretaceae. This genus gets its name from the Latin word Terminus, referring to the fact that the leaves appear at the very tips of the shoots. Trees of this genus are known as a good source of secondary metabolites such as cyclic triterpene and their derivatives, flavonoids and other aromatics. Tropical almond botanically equated as Terminalia catappa is a tall deciduous and erect tree reaching $25-40 \mathrm{~m}$, trunk $1-1.5 \mathrm{~m}$ in diameter. It is commonly called 'Indian almond', 'Malabar almond', 'Sea almond' and 'Tropical almond' ${ }^{[1]}$.

Terminalia catappa is known for its nutritional fruit and possesses medicinal benefits as well. Terminalia catappa has been recognized for its medicinally essential phytoconstituents, such as phenol, flavonoid, and carotenoid. Numerous pharmacological investigations have confirmed this plant's ability to exhibit antimicrobial, anti-inflammatory, anti-diabetic, antioxidant, hepato-protective, and anti-cancer activities, all of which support its traditional uses ${ }^{[2]}$.
A plant disease is usually defined as abnormal growth and dysfunction of a plant. Diseases are the result of some disturbance in the normal life process of the plant and may arise as a result of living and non-living causes. Biotic diseases are caused by living organisms (e.g., fungi, bacteria, and viruses) while abiotic diseases are caused by non-living environmental conditions, (e.g. soil compaction, wind, frost, soil salt damage, and girdling roots ${ }^{[3]}$.

Diseases can affect any part of a tree (root, stem, leaves). Foliar diseases are diseases that affect the leaves of a tree. They are caused by biotic agents. Research shows that most foliar diseases have diverse effects on plants if not managed or controlled. If identified early, they can be controlled or managed but if overlooked, it could bring about a reduction in plant population, reduction in plant yield, and decrease in plant's competitive ability. Plant disease has always been a challenge to plant growth and crop production in several parts of the world as they can affect plants by interfering with several processes such as absorbance and translocation of water and nutrients ${ }^{[4]}$.

Research by Cornell University (2019) showed a number of techniques that could be used to manage the spread of disease. 
These techniques include a selection of disease-resistant varieties, treatment of seeds, application of foliar fungicides, etc. The goal of plant disease management is to reduce the economic and aesthetic damage caused by plant diseases ${ }^{[6]}$. The practical reason for studying crop diseases is to develop economical control measures for management. Controls must be based on knowledge of the specific disease, pathogen life cycles, time and method of infection, the plant parts affected the method of causal agent dissemination and certain other agronomic and economic considerations ${ }^{[7,8]}$.

Fungi are known to be common pathogens associated with Terminalia catappa. The species' numerous importance to the community and environment makes it a species of interest. Therefore, there is a need to identify pathogens and then develop control measures to sustain this species and prevent the death of the plant. With the importance of Terminalia catappa being numerous, there is an inevitable need to study the diseases affecting it so that management techniques can be employed to curtail or address them. Disease management is a promising strategy for improving the growth and development of tree species ${ }^{[9,10]}$.

This study is to identify pathogens affecting the foliage of Terminalia catappa and develop methods for managing them.

Materials And Method

Sample Collection

The diseased leaves were plucked from the infected trees and taken to the mycology laboratory of Biological Sciences Department, Botany unit, Usmanu Danfodiyo University Sokoto. This was done so that fungal pathogens responsible for such diseases can be identified and then control measures can be developed.

\section{Laboratory Procedures for the Identification of the Fungal Pathogens \\ Media Preparation}

$39 \mathrm{~g}$ of potato dextrose agar (PDA) media was dissolved in $1000 \mathrm{ml}$ distilled water in a conical flask. $1 \mathrm{~g}$ of streptomycin was then added and cotton wool was used to seal the opening of the conical flask to make it airtight. The conical flask containing the media was then subjected to a gentle heat on a Thermo-plate until a homogeneous mixture of the media was obtained. The resulting media was then taken to an autoclave for sterilization at a temperature of $1210 \mathrm{C}$ for fifteen minutes (15 min). After the sterilization using an autoclave, the media was left to cool. $20 \mathrm{ml}$ of the liquid media was then poured into the petridishes. This was done in the inoculation room where the media was allowed to cool and solidify.

\section{Inoculation}

Diseased leaves were sorted and taken to the inoculation room in accordance with the diseased symptoms obtained from the field. The diseased area was cleaned with ethanol-soaked cotton wool and rinsed with distilled water. This was done to get rid of any pathogen (opportunists) that could be present, to avoid contamination. The diseased portion was then cut into small pieces $(2 \mathrm{~mm})$ and plated at the center of the petridishes containing the media. The plates were kept in the growth room for seven days after which growth was observed. Sub-culture was then carried to obtain a pure culture from the isolates ${ }^{[11]}$.

\section{Sub-Culturing of the Isolates}

Sub-culturing requires a sterile prepared media plate containing 39g of PDA media mixed with $1000 \mathrm{ml}$ of distilled water and $1 \mathrm{~g}$ of streptomycin. In the incubation room, the inoculation needle was cleaned with an ethanol soaked cotton wool and placed in a Bunsen burner to kill possible opportunists. The plate cultures containing fungus were opened a little to avoid the spores from coming out and prevent contamination of other plates present there. The inoculation needle was used to scoop a portion of the fungal culture and was streaked into the new sterile PDA plate. The plate was then left for 72 hours in hope for pure culture. A pure culture was still not obtained; the sub-culturing process was repeated ${ }^{[12,13]}$.

\section{Identification of the Fungal Pathogens}

After pure cultures of the organisms were obtained, the next step was the identification of the fungal pathogens. The organism was to be identified under a light microscope by placing a drop of lactophenol blue on a glass after which the inoculation needle was burned with a Bunsen flame (to get rid of possible spores on the tip of inoculation needle). The needle was used to pick a small portion of the colony and dropped into the lactophenol blue drop. The drop of lactophenol was covered by placing a cover slide at an angle of $450 \mathrm{C}$ to eliminate the air bubbles that may impede the view. The glass slide was covered with a cover glass and fixed to clip the microscope and adjusted using the different knobs until the organism can be clearly seen by switching between different lenses of the microscope. The organisms are identified through the use of Yang et al. (2017) manual.

\section{Fungicide Calculation}

Recommended fungicide rate for Suncozeb

$75 \mathrm{~g}=15$ litres

1 liter $=75 \div 15$

1 liter $=5 \mathrm{~g} / \mathrm{liter}$

For $300 \mathrm{ml}=0.3$ liters

$0.3 \times 5=1.5 \mathrm{~g}$; meaning 1.5 is the normal rate $(100 \%)$ for $300 \mathrm{ml}$ of distilled water.

$50 \%$ will be half of 1.5 which is $1.5 \div 2=0.75$.

$150 \%$ will be $1.5+0.75=2.25$

\section{Management Procedure Media Preparation}

Suncozeb, a fungicide for the management of food crops diseases was obtained. $39 \mathrm{~g}$ of potato dextrose ager media was dissolved in $1000 \mathrm{ml}$ of distilled water with $1 \mathrm{~g}$ of streptomycin. The mixture was heated on a thermo-plate to ensure the homogeneity of the mixture. The mixture was then 
autoclaved for total sterility and pour-plated under sterile conditions.

\section{Spore Suspension}

A process known as spore suspension was carried out. 500ml of distilled water was poured in a 1litre conical flask and plugged with cotton wool, then capped with aluminum foil. The distilled water was autoclaved at $121^{\circ} \mathrm{C}$ for 15 minutes. After the sterilization, the conical flask containing the sterile distilled water was allowed to cool down to room temperature. With the aid of a syringe, $10 \mathrm{ml}$ of the sterile distilled water was drawn and poured into the Petri dishes containing the stock culture of the test isolate. The water containing the spores was then drawn in a new syringe and poured into the already prepared media. This process was repeated for all of the test isolates. Then each media containing different spores of the test isolates was poured under sterile conditions in petridishes and allowed to cool.

\section{Fungicide Application}

$5 \mathrm{ml}$ of the sterile distilled water in the conical flask was measured using a syringe and poured into test tubes. The fungicide was then measured at different rates $(50 \%, 100 \%$ and, $150 \%$ ) and added to the sterile distilled water in the test tubes. A cork borer of size $7 \mathrm{~mm}$ was used to bore a hole in the already solidified media and with a micropipette, the dissolved fungicide was used to fill up the hole and the Petri dish was observed.

\section{Data Analysis}

The data collected were subjected to analysis of variance (ANOVA) procedure. Significant differences were separated in Duncan's Multiple Range Test (DMRT), using the Statistical Package for Social Science (SPSS).

\section{Results}

Cultural and Morphological Characteristics of Fungal Isolates Diseased leaves were cultured on PDA and fungal isolates were sub-cultured to obtain pure cultures. The fungal cultural characteristics were recorded and morphological features were viewed under a microscope and identified using the manual of Yang et al. (2017).

\section{Aspergillus niger}

Colonies of Aspergillus niger on PDA appear white initially but quickly turn black with conidial production. The reverse of the plate is pale yellow. Hyphae are septate and hyaline. Conidial heads are radiate initially but split into two at maturity.

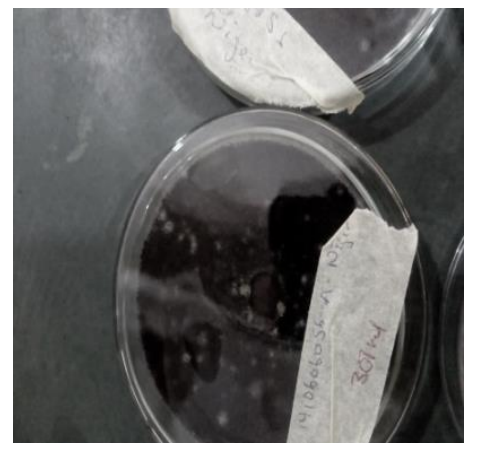

\section{Aspergillus ustus}

Plate1: Aspergillus niger

Aspergillus ustus appear dull brown with a yellow reverse side. Colonies are flat. Microscopically, the fungus is characterized by elongated conidial heads with bent Hülle cells scattered throughout the mycelium. The conidia are rough walled and spherical, ranging from green to yellow to brown.

\section{Aspergillus flavus}

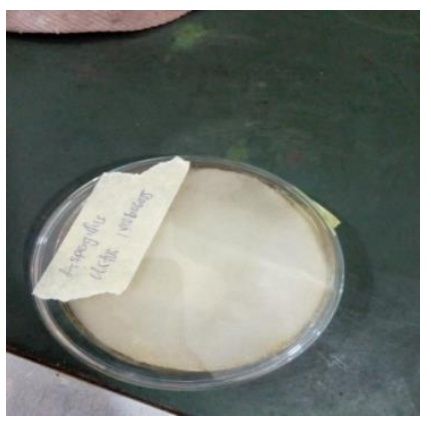

Plate 2: Aspergillus ustus

Aspergillus flavus colony characteristics growth on PDA appears green in color surrounded by a clear white zone. Growth was rapid covering the entire plate within 120hours of incubation. Microscopic examination of the mycelia of the fungus showed non-septate conidiophores arising from thickwalled foot cells. Each conidiophore ends in a terminal enlarged spherical swelling.

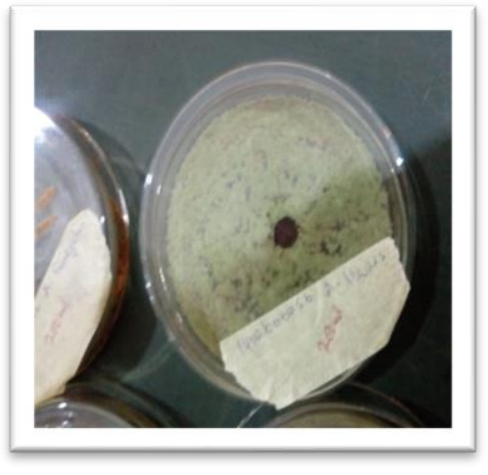

Plate 3: Aspergillus flavus 
TABLE 1: $50 \%$ is half of the recommended rate, $100 \%$ is the recommended rate and $150 \%$ is the recommended rate plus half of the recommended rate.

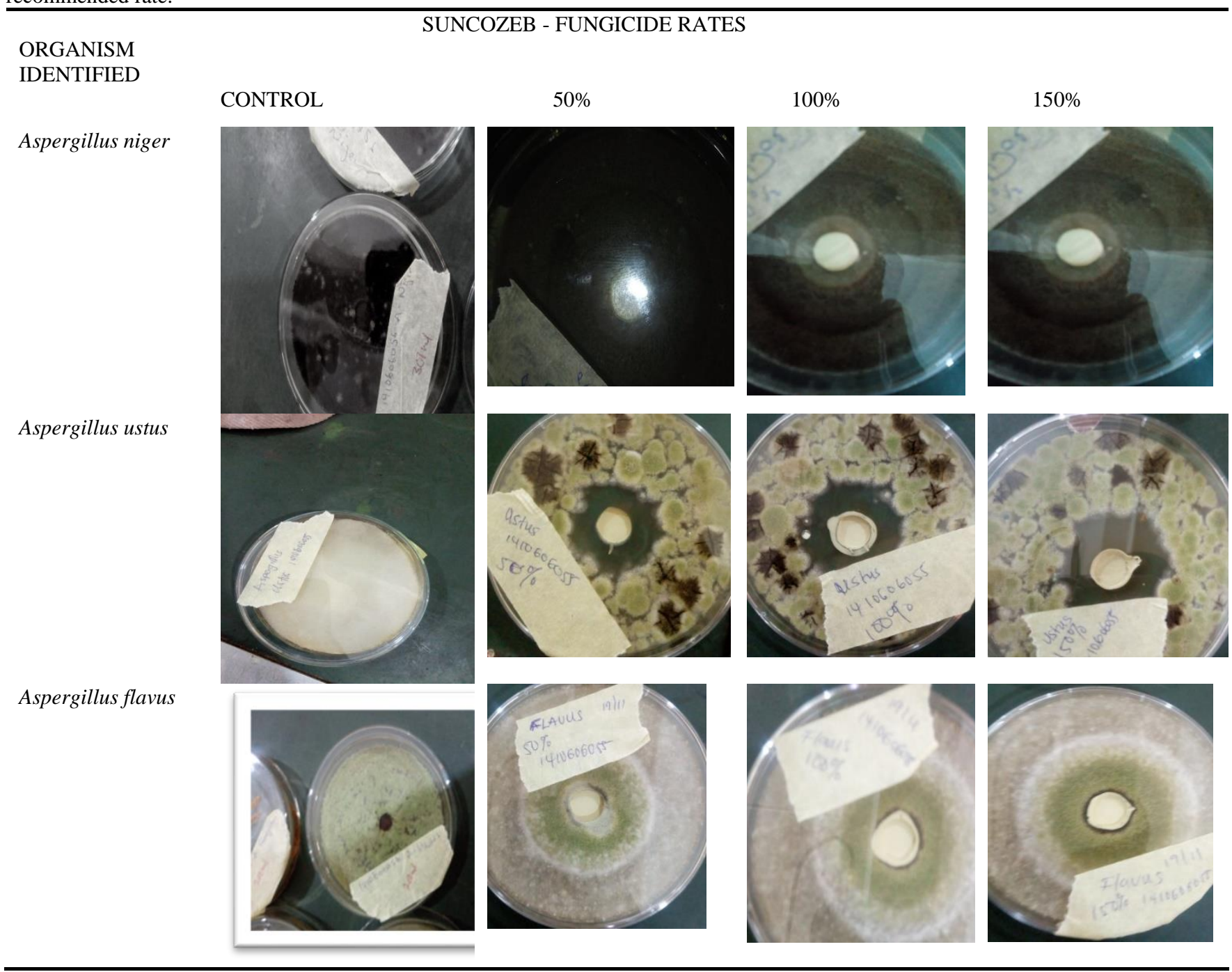

TABLE 2: ANALYZED DATA with means separated with Duncan's Multiple Range Test

FUNGICIDE RATES

\begin{tabular}{lcccc} 
TEST ISOLATES & CONTROL & $\mathbf{5 0 \%}$ & $\mathbf{1 0 0 \%}$ & $\mathbf{1 5 0 \%}$ \\
\hline Aspergillus niger & $22.67 \pm 0.667 \mathrm{~b}$ & $27.33 \pm 1.202 \mathrm{ab}$ & $32.33 \pm 0.667 \mathrm{a}$ & $20.22 \pm 0.667 \mathrm{~b}$ \\
& & & & \\
Aspergillus flavus & $15.67 \pm 0.33 \mathrm{~b}$ & $15.00 \pm 1.730 \mathrm{~b}$ & $17.67 \pm 0.667 \mathrm{a}$ & $9.67 \pm 1.730 \mathrm{c}$
\end{tabular}

$\begin{array}{llll}\text { Aspergillus ustus } \quad 21.33 \pm 0.882 \mathrm{~b} & 31.67 \pm 1.202 \mathrm{a} & 35.33 \pm 0.33 \mathrm{a} & 22.44 \pm 0.33 \mathrm{~b}\end{array}$

Values are means of the three replicates at the different rates. \pm indicates standard errors. Values with the same letter(s) within the same column are not significantly $(\mathrm{p} \leq 0.05)$ different from each other according to Duncan Multiple Range Test (DMRT). 


\section{Discussion}

Most of the leaves of Terminalia catappa in the study area were found to be plagued with one pathogenic fungus or the other. This is in line with the opinion of Ghose et al., (2010) who stated that the largest group of plant pathogens is the fungi, which could be because fungi are dispersed by spores. Most fungi rely on gravity to carry their spores down into air currents which will then carry them away to other places. The agents of fungi spore dispersal vary with wind, impact, water or insects (Talat and Eric, 2016).

Fungi usually produce spores which when carried to a plant can begin an infection. These spores may be carried from plants to plants by wind, water, insects, and animals. The foliar diseases of Terminalia catappa are attributed to high temperature and surrounding dead and decayed plant debris and weeds as remarked by Liang et al, (2006) in his research on resistance mechanism in Aspergillus infection shows the tolerance and growths of the fungi in high temperature. Normally fungi has a minimum growth temperature of $12^{\circ} \mathrm{C}$ $\left(54^{\circ} \mathrm{F}\right)$ and maximum growth temperature of $48^{\circ} \mathrm{C}\left(118^{\circ} \mathrm{F}\right)$. Fungi also thrive well in dead and decayed organic matter as according to Liang et al, (2006).

Although bio-chemicals are slowly replacing chemical pesticides, a complete global look at the scenario indicates that chemical pesticides like fungicides are still applied as a major approach to control pathogens and diseases of crops. The chemical used for this research, Suncozeb, is a broadspectrum fungicide for various fungal diseases. The chemical was more effective on the Aspergillus ustus at a $150 \%$ concentration of $35.33 \mathrm{~mm}$ measurements of the level of inhibition. This is followed by the Aspergillus niger with $32.33 \mathrm{~mm}$ level of inhibition at $150 \%$ and the least been Aspergillus flavus with its highest level of inhibition measured as $17.67 \mathrm{~mm}$, also at $150 \%$.

Suncozeb was observed to have reduced the spread growth of the pathogens in the petridishes containing the spores of the pathogens and PDA media. The zones of inhibition vary with the pathogen identified. This is in line with the findings of Hassan et al., (2013) who evaluated the effect of Mancozeb (which is similar to Suncozeb) on the mycelial growth of identified fungal pathogens and showed that mycelial growth was reduced at varying concentrations.

On the other hand, the PDA plate containing the control of each identified pathogen was observed to have full growth of the pathogen. It was observed that the higher the concentration the higher the zone of inhibition and the lower the concentration, the lower the inhibition zone. This is the case for all identified pathogens. It can thus be said that an increase in the concentration of the chemical (Suncozeb) will inhibit the growth of the pathogens.

Microscopic Features of Fungal Pathogen Responsible for the Foliar Diseases of Terminalia catappa
The features of Aspergillus species described in plate 1, plate 2 and plate 3 agrees with Jawaid, (2007) who found out that the microscopic characteristics for the identification of Aspergillus species are conidial heads, stipes, color and length, vesicle shape and seriation, metula covering, conidia size, shape and, roughness. The basic microscopic morphology is the same for all species. Hyphae are septate and hyaline. The conidiophores originate from the basal foot cell located on the supporting hyphae and terminate in a vesicle at the apex. Covering the surface of the vesicle entirely ("radiate" head) or partially at the upper surface ("columnar" head) are the flask-shaped phialides which are either uniseriate and attached to the vesicle directly or are biseriate and attached to the vesicle directly via a supporting cell called metula.

Other microscopic structures peculiar to certain species include Sclerotia, Sleistothecia, Aleuriconidia, and Hulle cells. These structures are of key importance in the identification of some Aspergillus species. Cleistothecium is produced during the sexual propagation of some Aspergillus species.Hulle cell is a large sterile cell bearing a small lumen. Similar to Cleistothecium, it is associated with the sexual stage of some Aspergillus species.

\section{Conclusion}

Results of the study showed that the foliage of Terminalia catappa in the study area was infected with fungal pathogens caused by Aspergillus species (Aspergillus niger, Aspergillus flavus, Aspergillus ustus). For the management of his diseases, Suncozeb, a chemical used in managing the disease of arable crops was obtained and although not completely effective as to inhibit the growth of the pathogen totally at the different concentrations tested, showed signs of effectiveness on disease management as there were zones of inhibition. Furthermore, more research should be conducted on the use of organic substances to combat these fungal pathogens, as constant use of inorganic chemicals could be harmful to consumers (animals and man) in the long run. Proper sanitation, crop rotation and, other cultural practices should be practiced to prevent the spread of these diseases.

\section{References}

[1]. Abdullah, A. (2017). Impact of Plant Diseases on Human Health. International Journal of Nutrition, Pharmacology, Neurological Diseases, 7, 21-22. doi:10.4103/ijnpnd.ijnpnd_24_17

[2]. Ghose, L. F. A. Neela, T.C. Chakaravorty, M.R. Ali and M.S.Alam. (2010). Incidence of leaf blight of mulberry plant and assessment of changes in amino acid and photosynthetic pigments of infected leaf. Pathology Journal 9:140-143pp

[3]. Hassan, W. A., Haleem, R. A, Saido, K. A. Chemical control of black foot disease caused by Ilyonectria 
radicicola on grapevine cuttings. Mesopotamia J Agric. (2013); 41:448-456.

[4]. Jawaid M. (2007): celiac diseases, retrieved from Www.fungi/mucursdestruction.com

[5]. Liang, X.Q., M. Luo and B.Z. Guo (2006): resistance mechanism to Aspergillus flavus infection and aflatoxin contam9ination in peanut (Arachis hypogea). Plant pathology journal 5: 115-124.

[6]. Maloy, O.C. (2005). Plant Disease Management. The Plant Health Instructor. doi: 10.1094/phi-i2005-0202-01

[7]. Mary Small, (2017). Colorado State University Extension. Plant pathology. 331-1. Retrieved from https://cmg.extension.colostate.edu/Gardennotes/33 1.pdf

[8]. National Population Census. (2015). Projected population, 2015-2020. Sokoto: National Population Commission Office

[9]. Talat M., Eric D. K. (2016). Disease Management. Retrieved

from https://wiki.bugwood.org/Disease_Management
[10]. Vaibhav, S., and P. Pratima. (2012). Physical Methods in Management of Plant Diseases. 10.13140/RG.2.1.1332.6480.

[11]. Venkatalakshmi P, Vadivel V, Brindha P. (2016). Phytopharmacological significance of Terminalia catappa L: An updated review

[12]. Vijay, A. (2015). An updated review of Terminalia catappa. Pharmacognosy Reviews, 9, 93-8. doi:10.4103/0973-7847.162103

[13]. Yang J., Tom H., Vijai B., Xiao-Lin C and Guotian L., (2017) "Plant Fungal Pathogenesis," Bio-Med Research International, Article ID 9724283, 2 pages, retrieved from; https://doi.org/10.1155/2017/9724283. 